\section{Artigos sobre carreira no LinkedIn: uma análise das categorias de composição, propósito} comunicativo e estilo

Articles about career on

LinkedIn: an analysis of categories of composition, communicative purpose and style

Adelane Brito RODRIGUES (UFPI) adelanerodrigues4@hotmail.com Francisco ALVES FILHO (UFPI) chicofilhoo@gmail.com

Recebido em: 13 de abr. de 2019. Aceito em: 15 de jul. de 2019.
RODRIGUES, Adelane Brito; ALVES FILHO, Francisco. Artigos sobre carreira no LinkedIn: uma análise das categorias de composição, propósito comunicativo e estilo. Entrepalavras, Fortaleza, v. 9, n. 3, p. 277-296, setdez/2019.

Resumo: Este artigo busca analisar as semelhanças entre artigos publicados no LinkedIn, por meio das análises das seguintes categorias: composição, propósito comunicativo e estilo. Para isso, selecionou-se um corpus com 5 artigos sobre o tema carreira, de autores diferentes, publicados nos anos de 2017 e 2018 no LinkedIn. Os principais teóricos que deram suporte para a construção do estudo foram Bakhtin (1979/2016), Askehave e Swales (2009), e Miller (2012). Conforme os resultados obtidos, os artigos publicados no LinkedIn, apesar de possuírem características próprias da escrita dos seus autores, apresentam similitudes, tais como o propósito comunicativo de ajudar os leitores a repensarem as suas carreiras e o estilo assinalado pela presença de relato pessoal, uso dos pronomes "eu", "nós" e "você", além do uso frequente de verbos no imperativo.

Palavras-chave: Gêneros discursivos. Rede social profissional. Conteúdo. 
v. 9 (3) 277-296 set-dez 2019

Abstract: This article seeks to analyze the similarities among articles published on LinkedIn, through the analysis of the following categories: composition, communicative purpose and style. For this, a corpus was selected with 5 articles on the career theme, from different authors, published in the years 2017 and 2018 on LinkedIn. The main theorists supporting the construction of the study were Bakhtin (1979/2016), Askehave and Swales (2009), and Miller (2012). According to the results obtained, the articles published on LinkedIn, despite having characteristics peculiar to the writing of their authors, present similarities, such as the communicative purpose of helping readers to rethink their careers and the style marked by the presence of personal reporting, use of pronouns "I", "we" and "you", in addition to the frequent use of imperative verbs.

Keywords: Discursive genre. Professional social network. Content.

\section{Introdução}

As atividades on-line modificam os usos da linguagem (BARTON; LEE, 2015). Como resultado dessas mudanças advindas da dinâmica digital, podemos considerar que o avanço das tecnologias digitais, a necessidade constante de interação humana e a participação em rede são fatores que propiciam a criação de novos gêneros textuais.

Os ambientes digitais, mais especificamente as redes sociais, permitem diferentes espaços para leitura e escrita. Com essas novas possibilidades de interação, surgem gêneros novos e protogêneros, que serão a base para gêneros futuros (BARTON; LEE, 2015), comprovando a tese de que os gêneros do discurso estão em constante renovação. Gêneros vigentes nas práticas sociais se tornam alicerces para novos gêneros que, posteriormente, repetirão o processo (DEVITT, 2004; MILLER, 2012).

Neste trabalho, propomo-nos a analisar o gênero digital artigo publicado na rede social LinkedIn para compreender como ocorre o funcionamento de três categorias dos gêneros discursivos: a estrutura composicional, o propósito comunicativo e o estilo, apoiando-nos, principalmente, em Bakhtin (2016), Askehave e Swales (2009) e Miller (2012). Para isso, analisamos um corpus composto por cinco artigos sobre carreira publicados no LinkedIn e de autoria diversa.

Desse modo, a realização deste estudo busca responder ao seguinte problema de pesquisa: quais são as características estruturais, propósitos comunicativos e fatores estilísticos de artigos publicados na rede social LinkedIn? Assim, os quatro objetivos que temos são descrever o processo composicional de cinco artigos publicados no LinkedIn, nos anos de 2017 e 2018; identificar o propósito comunicativo dos artigos; identificar os aspectos estilísticos de cada artigo e verificar as semelhanças entre os artigos analisados. 
Metodologicamente, esta pesquisa teve início por meio de uma pesquisa na Plataforma Scielo com a palavra "LinkedIn", mas não encontramos nenhum resultado com essa palavra nos títulos dos artigos científicos. Em seguida, realizamos a mesma pesquisa e ampliamos a busca para "todos os índices", assim, encontramos 7 resultados de pesquisas publicadas entre os anos de 2013 e 2018, porém, de acordo com a análise das palavras, observamos que os artigos acadêmicos encontrados estão mais direcionados à análise de redes sociais, inovação, Internet, seleção de pessoal, interatividade e gestão do conhecimento, inexistindo artigos que buscam descrever o gênero artigo do LinkedIn.

O estudo é relevante por discutir as características do gênero digital artigo frequentemente utilizado em uma rede social com fins profissionais. A compreensão que se pretende ter a partir desta pesquisa acerca da construção e finalidades dos artigos publicados no LinkedIn apresenta relevância social e acadêmica, visto que o conhecimento será relevante tanto para os usuários do LinkedIn que publicam artigos na rede quanto para os pesquisadores da área de linguagens.

Iniciaremos com uma breve explanação sobre o conceito de gêneros do discurso, seguida da apresentação dos elementos constitutivos de um gênero discursivo, como a estrutura composicional, o propósito comunicativo, e o estilo. Logo depois, discorreremos sobre a rede social LinkedIn, e, após, passaremos às análises e considerações finais.

\section{Referencial teórico}

Os gêneros do discurso

O embasamento teórico desta pesquisa se fundamenta, por um lado, nos postulados bakhtinianos sobre os gêneros do discurso, sendo como tipos relativamente estáveis de enunciados. Mas também iremos nos apoiar na visão de Swales (1990) de que os gêneros se caracterizam sobretudo por possibilitar que as comunidades discursivas efetivem seus propósitos comunicativos. Bakhtin também já abordara esta questão ao falar do intuito discursivo presente nos gêneros. Por isso, defendemos haver compatibilidade teórica entre as visões dos dois autores.

Para Bakhtin (2016), língua e vida se fundem por meio dos enunciados. Como as atividades humanas são múltiplas, as manifestações linguísticas também são diversas e, consequentemente, os gêneros do discurso são numerosos. Para Miller (2012), os gêneros são passíveis de mudança, evolução e deterioração. 
v. 9 (3)

277-296 set-dez 2019

Os gêneros discursivos não são criados de modo fortuito. Assim como os enunciados, os gêneros estão inseridos em uma realidade social e são influenciados e determinados pelas atividades humanas. Sobre esse caráter dos gêneros discursivos, compartilhamos da mesma visão de Miller (2012) que acentua a necessidade de compreensão do sistema coletivo no qual os gêneros estão inseridos por meio do conhecimento e análise da natureza da coletividade. Tem-se, desse modo, na elaboração dos gêneros, uma associação com gêneros já existentes, em virtude de os fenômenos constitutivos do sistema da língua não serem novos, mas inseridos em um processo contínuo de experimentação e elaboração com gêneros e estilos existentes (BAKHTIN, 2016).

Devido a essa hibridização do discurso, os gêneros discursivos são classificados em primários e secundários. Conforme Bakhtin (2016), os gêneros primários são mais simples e formados em situações em que a comunicação discursiva é imediata. Os gêneros secundários, por outro lado, têm maior complexidade e são criados em situações mais sistematizadas, principalmente nas situações em que a escrita é predominante. Como exemplo de gênero primário, tem-se um diálogo entre duas pessoas, enquanto um artigo acadêmico é um exemplo de gênero secundário.

Os elementos constitutivos de um gênero discursivo

Os gêneros do discurso são constituídos por enunciados, sendo que estes são caracterizados por três elementos: o conteúdo temático, o estilo e a construção composicional (BAKHTIN, 2016). Ao mesmo tempo em que os enunciados são individuais, eles também são sociais. De modo concomitante, os três elementos que compõe os enunciados são peculiares, também, aos gêneros do discurso.

Sobre a organização de um gênero discursivo, Lima (2012, p. 164), seguindo os postulados bakhtinianos, declara que:

a noção de gênero em Bakhtin comporta uma arquitetônica que inclui conteúdo temático, unidade temática, forma composicional, estilo, entonação expressiva, autor, destinatário e aponta necessariamente para uma dimensão extraverbal na medida em que inclui os modos de produção e circulação, os fatores sócio-históricos bem como os valores constituídos socialmente. 
Compreende-se, assim, que um gênero discursivo é composto por elementos que reproduzem os aspectos sociais e individuais do meio em que o gênero circula e que permitem a análise de um gênero além do seu aspecto estrutural. Nas próximas seções, abordaremos a estrutura composicional (BAKHTIN, 2016), o propósito comunicativo (SWALES, 1990) e o estilo (BAKHTIN, 2016).

As escolhas pela categoria de propósito comunicativo de Swales e exclusão da categoria de conteúdo temático de Bakhtin justificam-se por entendermos que o propósito comunicativo atende melhor à função de evidenciar a finalidade do autor do LinkedIn ao escrever seu artigo. Mesmo assim, como forma de situar o leitor deste estudo, no momento das análises dos artigos do LinkedIn haverá uma seção sobre as temáticas de cada um deles. Começaremos pela estrutura composicional.

\section{A estrutura composicional}

Apesar de haver uma diferença entre os enunciados, há, entre eles, certas particularidades compartilhadas referentes a aspectos estruturais comuns (BAKHTIN, 2016). A construção composicional específica do enunciado, entretanto, não é o fator determinante para a conceituação de um gênero. Em Bakhtin (2016, p. 43), vemos que "o gênero escolhido nos sugere os tipos e os seus vínculos composicionais".

O propósito a ser atingido por um enunciador será concretizado pela escolha de um gênero específico. A forma desse gênero, isto é, a disposição das informações apresentadas, é o elemento denominado estrutura composicional.

Sobre o aspecto composicional do gênero, concordamos com Bakhtin (2016, p. 39) quando autor considera que

nós aprendemos a moldar o nosso discurso em formas de gênero e, quando ouvimos o discurso alheio, já adivinhamos o seu gênero pelas primeiras palavras, adivinhamos certo volume (isto é, uma extensão aproximada do conjunto do discurso), uma determinada construção composicional, prevemos o fim, isto é, desde o início temos a sensação do conjunto do discurso que, em seguida, apenas se diferencia no processo de fala.

Verificamos, dessa maneira, que, apesar de a estrutura composicional não ser o aspecto definidor de um gênero, ela é um dos fatores que contribuem para a sua compreensão. Outro elemento a ser analisado no estudo dos gêneros é o propósito comunicativo, descrito na próxima seção. 
v. 9 (3)

277-296

\section{O propósito comunicativo}

Apresentar uma definição para propósito comunicativo não é uma tarefa simples, visto que esse conceito diz respeito ao objetivo socialmente construído por um grupo de pessoas que utilizam um determinado gênero em contexto semelhante. Para os teóricos da área de gêneros do discurso, o propósito comunicativo é entendido como o fundamento lógico, o fator necessário de ser ensinado e aquilo que distingue gêneros diferentes. (SWALES, 1990; ASKEHAVE; SWALES, 2009; MILLER, 2012).

Vemos, quanto ao propósito comunicativo, uma certa dificuldade em conceituá-lo precisamente. Cabe ressaltar que o propósito comunicativo de um gênero, tal como visto em Askehave e Swales (2009), não se limita aos aspectos formais.

Para a determinação do propósito comunicativo, torna-se necessário enxergar além da estrutura visível, sendo preciso ler nas entrelinhas e estabelecer relações entre os textos e o contexto no qual o gênero é utilizado. Por isso, neste trabalho compreendemos o propósito como a finalidade socialmente reconhecida pelos autores dos artigos publicados no LinkedIn. Além da estrutura composicional e do propósito, o estilo é outra categoria observável ao se estudar os gêneros discursivos. Na próxima seção, especificaremos o estilo.

O estilo

O estilo é uma característica inerente a cada gênero discursivo, ele representa as escolhas feitas pelo autor a partir de uma dada realidade. Para Bakhtin (2016, p. 18), "o estilo integra a unidade de gênero do enunciado como seu elemento" e se apresenta sob duas formas: o estilo individual e o estilo do gênero.

O estilo individual, como o nome sugere, retrata a individualidade do enunciador, ou seja, as opções léxico-gramaticais escolhidas por ele no momento de uso do gênero, e o estilo do gênero refere-se às escolhas linguísticas socialmente padronizadas para a construção de textos de um determinado gênero. Como exemplo de uso do estilo individual, podemos citar os gêneros da literatura de ficção, enquanto os documentos oficiais e as ordens militares são exemplos de estilo do gênero (BAKHTIN, 2016). Compreender essa diferença éum fator importante para o desenvolvimento de análises dos gêneros discursivos, pois permite identificar, por exemplo, as regularidades presentes em um gênero específico. 
Entende-se, pois, que quanto à análise do estilo, dentre os elementos que podem ser analisados, por evidenciarem as preferências individuais dos autores, estão a seleção lexical, o uso de determinadas expressões e as escolhas gramaticais. Tais elementos serão priorizados neste estudo durante a análise dos artigos publicados no LinkedIn.

\section{O LinkedIn}

O LinkedIn éuma rede social profissional, isto é, diferentemente de outras redes sociais como o Facebook e o Instagram que são mais voltadas para o entretenimento, o foco do Linkedin é o mercado de trabalho. Sendo frequentemente conhecida como "currículo on-line", essa rede social permite muito mais do que a inserção de um currículo em um suporte digital. Conforme informações apresentadas no site global da rede social ${ }^{1}$ e tendo como base o ano de 2018, o LinkedIn possui mais de 590 milhões de membros registrados no mundo e mais de 35 milhões no Brasil.

Apresentada como a maior rede social profissional do mundo, o LinkedIn não é um mero local de exposição de currículos inertes. Além da possibilidade de campos para a inserção da experiência profissional do utilizador, tanto atual quanto passada, a rede também possibilita a inclusão da formação acadêmica, competências, recomendações dadas por outras pessoas - e conquistas.

Pode-se, igualmente, enviar pedidos de conexão a outros profissionais, visualizar e candidatar-se a vagas de emprego, e compartilhar artigos, fotos, documentos, vídeos ou publicações curtas de até 1.300 caracteres na linha do tempo. A possibilidade de publicação é, certamente, o fator que propicia a ampliação de relacionamentos profissionais e da visibilidade de um perfil.

As pessoas que usam o LinkedIn utilizam a rede não apenas para ver currículos, mas para adquirir conhecimento, construir uma marca pessoal e fortalecer os relacionamentos profissionais. Esses objetivos podem ser alcançados por meio da leitura e da publicação de artigos.

Os artigos estão visíveis na plataforma de publicação do LinkedIn, antigamente chamada de Pulse e disponibilizada ao público brasileiro no ano de 2015. Como forma de apresentar a nova funcionalidade da rede social, um dos editores do LinkedIn na

\footnotetext{
${ }^{1}$ LINKEDIN. Statistics. [2018]. Disponível em: <https://news.linkedin.com/about-us?fbclid=Iw AR08el6bLWMZogueuIDNqWf3vkesxrh8LAhRxAhI41NGw08xr4COaH2sblQ\#statistics>. Acesso em: 6 dez. 2018.
} 
v. 9 (3)

277-296

set-dez

2019

época, Rodrigo Brancatelli (2015), publicou um artigo relatando suas possibilidades. O artigo de Brancatelli é importante por ter sido escrito com a finalidade de apresentar o Pulse para favorecer a publicação de artigos nessa rede social.

Em seu artigo, Brancatelli (2015) incentiva as pessoas a produzirem conteúdo no Linkedin. Uma das primeiras formas de encorajar a escrita de artigos utilizada por Brancatelli é afirmar que "a parte mais legal é que você não precisa ser Influencer para que os 380 milhões de usuários do LinkedIn leiam o seu artigo". Nota-se, então, que o LinkedIn Pulse é descrito como uma funcionalidade sem restrições de uso, ou seja, aberta a todos os utilizadores da rede e não apenas às pessoas que recebem o selo de Influencer - selo dado como reconhecimento de trabalho.

Brancatelli (2015) detalha o que escrever nos artigos. Segundo ele, é possível escrever sobre experiências profissionais, atentando-se sempre para a audiência a ser atingida, escolher bem o título do artigo, para não correr o risco de ser ignorado pela audiência, manter uma constância nas publicações, escolher uma boa imagem para ser inserida no topo do artigo e não ter medo de compartilhá-lo com a sua rede de contatos.

O segundo incentivo dado como meio de os utilizadores começarem a escrever é a informação de que os melhores artigos, analisados pela equipe de curadoria do LinkedIn, são destacados na rede social. Ao se ter um artigo destacado na plataforma, o autor tem mais chances de ter o seu perfil visto.

\section{Metodologia}

Esta pesquisa é de natureza básica e de caráter descritivo (GIL, 2010), com o corpus composto por cinco artigos, de autores diferentes, retirados do LinkedIn. Todos os artigos contêm "carreira" como tema e foram publicados nos anos de 2017 e 2018.

Os dois critérios paraa seleção dos artigos foram o pertencimento ao tema "carreira" e a necessidade de o autor do artigo do LinkedIn estar na rede de contatos dos autores deste estudo. A existência desse segundo critério justifica-se pelo fato de um conhecimento prévio acerca de autores do LinkedIn que já publicam artigos sobre o tema carreira.

$\mathrm{Na}$ análise, a ferramenta WordCounter $360^{\circ}$ será utilizada para a contagem da quantidade de frases e de palavras por frase. Destacamos, ainda, que a relação entre cotexto e contexto estará presente em todas as análises. 


\section{Análise dos dados}

Perfil de autoria dos artigos

Os autores dos artigos selecionados possuem atuações profissionais distintas e essa atuação impacta fortemente na escolha do assunto a ser tratado no artigo por dois motivos: maior domínio sobre o assunto e desejo de mostrar aos outros o seu conhecimento, ou seja, posicionar-se como um profissional qualificado.

As formações acadêmicas dos autores são, respectivamente, Ciências da Computação, Psicologia, Relações Internacionais, Engenharia Elétrica e Análise de Sistemas. Cabe ressaltar as múltiplas atuações dos autores, sendo muitos deles, criadores de cursos, escritores e palestrantes.

Essa característica multifacetada da carreira de cada autor contribui para que a maioria dos artigos sejam relatos de experiências vividas. Abaixo, temos as informações disponibilizadas por cada um deles sobre suas atuações:

1) Patrick Pedreira - "Professor Mestre em Ciência da Computação, doutorando na USP, coordenador de cursos de graduação (Computação), autor do livro "Carreira sem atalhos" e, acima de tudo, um amante da tecnologia e da docência".

2) Taís Targa - "Psicóloga, Coach, Mestre em Educação, Job Hunter, Especialista em Recolocação e Carreira. Reconhecida comouma das15brasileiras quemais influenciaramoLinkedIn em 2016 - LinkedIn Top Voices. Vlogueira, palestrante, escritora, viciada em redes sociais e empreendedora. Diretora da empresa TTarga Carreira e Recolocação".

3) Matheus de Souza - "Nômade digital que escreve e empreende, considerado pelo LinkedIn como o terceiro brasileiro mais influente da rede no ano de 2016 em sua lista de Top Voices. Sou cofundador do be freela, portal focado em carreira freelancer, trabalho remoto e nomadismo digital".

4) Dimitri Vieira - "Engenheiro eletricista por formação, marqueteiro por vocação, entusiasta de belas histórias e profissional de Marketing de Conteúdo. Além de membro do time de Growth da Rock Content, editor-chefe do Comunidade Rock Content e "escritor de LinkedIn" por hobby". 
v. 9 (3)

277-296

set-dez

2019

5) Eberson Terra - "Profissional com 13 anos de experiência na área de tecnologia, processos, qualidade de software e gestão de projetos".

Pela análise do conteúdo apresentado nas descrições, verificamos que eles apresentam informações que vão além da indicação do cargo profissional. Os autores utilizam informações sobre seus níveis de formação acadêmica, autoria de livros, interesses temáticos, reconhecimentos adquiridos devido ao próprio uso do LinkedIn, vícios e experiências profissionais anteriores.

Os autores consideram importante mostrar ao público o máximo de informações tidas como relevantes sobre suas vivências profissionais. Isso não significa, entretanto, que as informações são extensas, mas necessárias para descrever o autor do artigo. Por meio das informações, nota-se o interesse dos autores em mostrar aspectos de suas vidas pessoais, e os temas que lhes são relevantes.

\section{Temáticas}

Os temas dos artigos são variados, porém todos seguem a finalidade do LinkedIn de ser uma rede voltada para o desenvolvimento profissional. Dessa maneira, os artigos que constituem o corpus deste estudo possuem como tema a construção de uma carreira de sucesso, mudança de carreira e relação com o trabalho.

Os autores abordam os assuntos de maneira compreensível, com uma linguagem parcialmente acessível, visto que o público precisa conhecer a situação explicitada para um bom entendimento do artigo. Uma linguagem totalmente especializada restringiria a quantidade de leitores e, principalmente, a interação com o conteúdo. Os assuntos não são tratados com uma abordagem científica, mas com base nas experiências dos autores e nas suas percepções sobre o mercado de trabalho, como evidenciam os exemplos seguintes:

Artigo 1 (A1): "Na minha concepção seriam quatro os passos para se alcançar o sucesso profissional, independente da área de atuação".

Artigo 2 (A2): "Tenha clareza de quais são os seus talentos, do que te dá prazer e de que maneira poderia usar os seus dons a serviço dos outros". 
Artigo 3 (A3): "O problema é que muitos acabam se acostumando com uma realidade do tipo e não conseguem enxergar uma mudança no horizonte. E pior: se tornam reféns de seus salários que pagam suas contas".

Artigo 4 (A4): "Em algum momento na vida, todos nós precisamos escolher entre nadar rumo a um objetivo ou simplesmente ficar à deriva e ver para onde seremos levados. Conscientemente ou não, todos nós tomamos essa decisão". Artigo 5 (A5): "Talvez nem a sua empresa deseja que você fique nesta angústia por ela!".

Verificamos, com os trechos acima, que todos os artigos possuem semelhanças quando os autores trazem para o texto situações comuns do mercado de trabalho.

\section{A estrutura composicional}

Os cinco artigos se assemelham na estrutura composicional, mas apresentam alguns contrastes, conforme as categorias mostradas no quadro 1.

Quadro 1 - Estrutura composicional dos artigos

\begin{tabular}{|l|c|c|c|c|c|c|}
\hline & A1 & A2 & A3 & A4 & A5 & $\begin{array}{c}\text { Total de } \\
\text { ocorrências } \\
\text { da categoria }\end{array}$ \\
\hline Categorias & \multicolumn{7}{|l|}{} & X & X & X & X & X & 5 \\
\hline Introdução & & X & & & & 1 \\
\hline Desenvolvimento numerado & $\mathrm{X}$ & & & & $\mathrm{X}$ & 2 \\
\hline $\begin{array}{l}\text { Desenvolvimento com } \\
\text { perguntas }\end{array}$ & & & $\mathrm{X}$ & $\mathrm{X}$ & & 2 \\
\hline $\begin{array}{l}\text { Desenvolvimento com } \\
\text { subtítulos }\end{array}$ & & & $\mathrm{X}$ & $\mathrm{X}$ & & 2 \\
\hline $\begin{array}{l}\text { Citaç̃̃es de filmes, livros, } \\
\text { músicas ou filósofos }\end{array}$ & & & $\mathrm{X}$ & $\mathrm{X}$ & $\mathrm{X}$ & 3 \\
\hline Menção a outros textos & & & & & 1 \\
\hline $\begin{array}{l}\text { Conclusão com a indicação } \\
\text { de um livro publicado pelo } \\
\text { próprio autor }\end{array}$ & $\mathrm{X}$ & & & & & \\
\hline Conclusão & & $\mathrm{X}$ & $\mathrm{X}$ & $\mathrm{X}$ & & 3 \\
\hline Agradecimento pela leitura & & & & $\mathrm{X}$ & & 1 \\
\hline Descrição profissional & $\mathrm{X}$ & $\mathrm{X}$ & $\mathrm{X}$ & & $\mathrm{X}$ & 4 \\
\hline
\end{tabular}

Fonte: elaborado pelos autores. 
v. 9 (3)

277-296 set-dez 2019

Os elementos mais recorrentes, como mostram os números no Quadro 1, são a introdução, o desenvolvimento numerado e com subtítulos, as citações de outros textos do LinkedIn, a conclusão em um formato regular e a descrição profissional. Assim como os textos de blogs na internet são escritos de modo a atrair a atenção do leitor, os autores do LinkedIn utilizam-se dos recursos mencionados no quadro 1 para deixar os seus artigos interessantes ao leitor, para que sejam, efetivamente, lidos do início ao fim.

\section{O propósito}

Identificamos o propósito de cada artigo, conforme os seguintes segmentos textuais apresentados a seguir:

\section{A1}

1. "Conhecendo quem somos em todas as dimensões podemos escolher as ações que nos guiem na direção profissional que se encaixem naquilo que somos e que queremos. Estar motivado para fazer o que se vai fazer é fundamental e isso só se consegue se propósito e carreira conversarem diretamente um com o outro."

2. "As pessoas precisam saber quem é você e que você faz bem aquilo que se propõe."

\section{A2}

1. "Atualmente tem muita gente querendo empreender, às vezes, transformando seu hobby ou suas paixões em fonte de renda".

2. "Dê o primeiro passo e se esforce. Tenha clareza de quais são os seus talentos, do que te dá prazer e de que maneira poderia usar os seus dons a serviço dos outros".

\section{A3}

1. "Muitas vezes você terá que criar as suas próprias oportunidades".

2. "Você precisa aprender a dizer 'não"'. 


\section{A4}

1. "Não se rotule pela sua formação acadêmica, ou por nenhum outro evento".

2. "Estude e aprenda sempre, e não apenas sobre sua área de atuação".

\section{A5}

1. "Necessidade de entendermos nosso papel de protagonista de nossas próprias carreiras, buscando um significado para o que fazemos".

2. "As pessoas interpretam e fazem de seus propósitos, cruzes difíceis de carregar".

Os autores conduzem o leitor a refletir sobre seus interesses, definir prioridades, serumaprendizcontínuoeassumiraresponsabilidade pela sua própria carreira. Todos os trechos apresentados apontam para a noção de que cada artigo possui um propósito específico e, também, de que um único propósito geral pode abranger os 5 artigos.

A existência de um propósito geral justifica-se pela temática compartilhada. É possível perceber em todos os fragmentos a presença de conselhos sobre a vida profissional e de palavras ou expressões relacionadas a ela, tais como "direção profissional", "empreender", "fonte de renda", "talentos", "criar as suas próprias oportunidades", "área de atuação", "papel de protagonista de nossas próprias carreiras".

A partir das evidências linguísticas percebidas acima, identificamos o propósito de cada artigo, de acordo com as informações apresentadas no Quadro 2, cujos trechos em negrito correspondem a marcações feitas pelos próprios autores dos artigos no Linkedin.

Quadro 2 - Propósito comunicativo dos artigos

\begin{tabular}{|l|l|l|}
\hline \multicolumn{1}{|c|}{ Artigo } & \multicolumn{1}{|c|}{ Propósito } & \multicolumn{1}{c|}{ Trecho do artigo } \\
\hline A1 & $\begin{array}{l}\text { Apresentar o que fazer para } \\
\text { alcançar uma carreira de } \\
\text { sucesso. }\end{array}$ & $\begin{array}{l}\text { "Para isso, sugiro refletir } \\
\text { bastante responder às seguintes } \\
\text { perguntas: Quem sou eu? O } \\
\text { que eu gosto de fazer? Em que } \\
\text { atividade eu sou bom?" }\end{array}$ \\
\hline A2 & $\begin{array}{l}\text { Mostrar como fazer de um } \\
\text { hobby a sua profissão. }\end{array}$ & $\begin{array}{l}\text { "Quero te dizer que é viável } \\
\text { ganhar dinheiro com a } \\
\text { sua paixão. Mas é preciso } \\
\text { persistência, disciplina e saber } \\
\text { vender." }\end{array}$ \\
\hline
\end{tabular}


v. 9 (3)

277-296

set-dez

2019

\begin{tabular}{|l|l|l|}
\hline A3 & $\begin{array}{l}\text { Incentivar cada leitor a se } \\
\text { tornar protagonista em sua } \\
\text { carreira. }\end{array}$ & $\begin{array}{l}\text { "E nessa de sobreviver aceitamos } \\
\text { qualquer trabalho que aparecer. } \\
\text { Principalmente se você é jovem. } \\
\text { A boa notícia é que, diferente do } \\
\text { tempo dos nossos pais e avós, não } \\
\text { precisa mais ser assim. Não } \\
\text { depois de um tempo, pelo menos." }\end{array}$ \\
\hline $\mathbf{A 4}$ & $\begin{array}{l}\text { Ajudar, por meio do relato de } \\
\text { sua própria vivência, as pessoas } \\
\text { que estão indecisas sobre } \\
\text { suas carreiras e mostrar que é } \\
\text { possível mudar de carreira. }\end{array}$ & $\begin{array}{l}\text { "Afinal, seu curso define } \\
\text { simplesmente sua formação } \\
\text { acadêmica, que, além de um } \\
\text { diploma, rende experiência e } \\
\text { algumas linhas no seu currículo. } \\
\text { O restante depende de você.." }\end{array}$ \\
\hline A5 & $\begin{array}{l}\text { Levar o leitor a refletir sobre } \\
\text { sua relação com o trabalho e } \\
\text { a importância de manter um } \\
\text { equilíbrio nessa relação. }\end{array}$ & $\begin{array}{l}\text { "[...] cuidado, sua dedicação ao } \\
\text { trabalho pode estar consumindo } \\
\text { mais do que um tempo precioso } \\
\text { de sua vida particular." }\end{array}$ \\
\hline
\end{tabular}

Fonte: elaborado pelos autores.

Podemos, então, verificar que o propósito de todos os artigos está associado à orientação de carreira. Desse modo, é possível reconhecer o propósito geral comum de ajudar os leitores a repensarem as suas trajetórias profissionais.

Cada autor pretende ser uma espécie de guia para o leitor do texto, não como alguém superior, mas como uma pessoa que pode fornecer orientações por já ter uma certa experiência e, também, por estar do lado de fora da situação vivenciada pelo leitor. Já com relação à visão do leitor acerca deles, os autores pretendem ser vistos como profissionais competentes, confiáveis e prestativos, no sentido de serem reconhecidos como alguém que se pode contar.

O estilo

Na visão bakhtiniana (BAKHTIN, 2016), o estilo é um elemento intrínseco ao enunciado como também aos gêneros do discurso. Para Bakhtin (2016, p. 22), "a própria escolha de uma determinada forma gramatical pelo falante é um ato estilístico".

Nas análises do corpus desta pesquisa, identificamos marcas estilísticas recorrentes como o uso de verbos no infinitivo, o uso do imperativo, o uso do pronome "você", o uso de verbos no futuro do pretérito e o uso de expressões que promovem uma conversa com o leitor. Constatamos essas marcas caracterizadoras do estilo em todos os cinco artigos aqui analisados, conforme o Quadro 3. Os trechos em negrito correspondem a marcações feitas pelos próprios autores dos artigos no LinkedIn. 
Quadro 3 - Estilo dos artigos

\begin{tabular}{|c|c|c|c|c|c|}
\hline & A1 & $\mathrm{A} 2$ & A3 & $\mathrm{A}_{4}$ & A5 \\
\hline \multicolumn{6}{|l|}{$\begin{array}{l}\text { Traço } \\
\text { estilístico }\end{array}$} \\
\hline $\begin{array}{l}\text { Uso de } \\
\text { verbos no } \\
\text { infinitivo }\end{array}$ & $\begin{array}{l}\text { Aprender } \\
\text { com os } \\
\text { outros é } \\
\text { talvez, a } \\
\text { única forma } \\
\text { de atalho não } \\
\text { prejudicial. }\end{array}$ & $\begin{array}{l}\text { Conhecer } \\
\text { as } \\
\text { estratégias } \\
\text { para vender } \\
\text { adequada- } \\
\text { mente o } \\
\text { seu produto } \\
\text { ou serviço é } \\
\text { algo muito } \\
\text { importante. }\end{array}$ & $\begin{array}{l}\text { Vestir a } \\
\text { sua própria } \\
\text { camisa é } \\
\text { aprender a } \\
\text { dizer "não". }\end{array}$ & $\begin{array}{l}\text { Conhecer } \\
\text { mais sobre } \\
\text { outros } \\
\text { assuntos } \\
\text { ajuda a } \\
\text { expandir } \\
\text { a mente } \\
\text { e ainda te } \\
\text { torna uma } \\
\text { pessoa mais } \\
\text { interessante. }\end{array}$ & $\begin{array}{l}\text { Ter } \\
\text { equilíbrio } \\
\text { entre vida } \\
\text { profissio- } \\
\text { nal e } \\
\text { pessoal } \\
\text { não quer } \\
\text { dizer que } \\
\text { você não } \\
\text { seja 100\% } \\
\text { dedicado. }\end{array}$ \\
\hline $\begin{array}{l}\text { Uso do } \\
\text { modo } \\
\text { imperativo }\end{array}$ & $\begin{array}{l}\text { Procure } \\
\text { conhecer } \\
\text { um pouco } \\
\text { destes temas } \\
\text { e usufrua da } \\
\text { tecnologia } \\
\text { como sua } \\
\text { aliada. }\end{array}$ & $\begin{array}{l}\text { Dê o } \\
\text { primeiro } \\
\text { passo e se } \\
\text { esforce. }\end{array}$ & $\begin{array}{l}\text { Não aceite } \\
\text { novos } \\
\text { projetos que } \\
\text { não estejam } \\
\text { alinhados } \\
\text { com os seus } \\
\text { valores. }\end{array}$ & $\begin{array}{l}\text { Jamais deixe } \\
\text { de ser um } \\
\text { aprendiz. }\end{array}$ & $\begin{array}{l}\text { Reflita } \\
\text { sobre sua } \\
\text { família. }\end{array}$ \\
\hline $\begin{array}{l}\text { Uso do } \\
\text { pronome } \\
\text { "você" }\end{array}$ & $\begin{array}{l}\text { As pessoas } \\
\text { precisam } \\
\text { sabem quem } \\
\text { é você e que } \\
\text { você faz bem } \\
\text { aquilo que se } \\
\text { propõe. }\end{array}$ & $\begin{array}{l}\text { É nesta } \\
\text { etapa que } \\
\text { você vai } \\
\text { pensar } \\
\text { sobre } \\
\text { aonde quer } \\
\text { chegar. }\end{array}$ & $\begin{array}{l}\text { Você } \\
\text { nunca será } \\
\text { protagonista } \\
\text { enquanto } \\
\text { trabalhar } \\
\text { apenas para } \\
\text { pagar as } \\
\text { contas. }\end{array}$ & $\begin{array}{l}\text { O resto } \\
\text { depende de } \\
\text { você. }\end{array}$ & $\begin{array}{l}\text { Talvez } \\
\text { nem a sua } \\
\text { empresa } \\
\text { deseja } \\
\text { que você } \\
\text { fique nesta } \\
\text { angústia } \\
\text { por ela! }\end{array}$ \\
\hline $\begin{array}{l}\text { Verbos no } \\
\text { futuro do } \\
\text { pretérito }\end{array}$ & $\begin{array}{l}\text { Mas } \\
\text { independen- } \\
\text { temente da } \\
\text { definição } \\
\text { de sucesso, } \\
\text { alguns passos } \\
\text { poderiam } \\
\text { ser elencados } \\
\text { neste } \\
\text { processo. }\end{array}$ & $\begin{array}{l}\text { O que você } \\
\text { decidiria } \\
\text { fazer? }\end{array}$ & $\begin{array}{l}\text { Mostrar } \\
\text { como eu } \\
\text { poderia } \\
\text { ser útil e } \\
\text { ganhar uma } \\
\text { promoção já } \\
\text { no próximo } \\
\text { ano. }\end{array}$ & $\begin{array}{l}\text { Eu iria te } \\
\text { surpreender. }\end{array}$ & $\begin{array}{l}\text { Mas você } \\
\text { saberia } \\
\text { dizer } \\
\text { quando } \\
\text { e como } \\
\text { chegar ao } \\
\text { equilíbrio? }\end{array}$ \\
\hline $\begin{array}{l}\text { Conversa } \\
\text { com o } \\
\text { leitor }\end{array}$ & $\begin{array}{l}\text { Você curtiu o } \\
\text { texto? }\end{array}$ & & & $\begin{array}{l}\text { Familiar o } \\
\text { título, não é? }\end{array}$ & \\
\hline
\end{tabular}

Fonte: elaborado pelos autores (grifos nossos).

Para uma melhor compreensão visual, os traços estilísticos encontrados nos artigos estão sintetizados no Quadro 4. 
v. 9 (3)

277-296

set-dez

2019

Quadro 4 - Síntese dos estilos dos artigos

\begin{tabular}{|c|c|c|c|c|c|}
\hline & $\mathrm{A} 1$ & $\mathrm{~A} 2$ & A3 & $\mathrm{A}_{4}$ & A5 \\
\hline \multicolumn{6}{|l|}{ Traço estilístico } \\
\hline $\begin{array}{l}\text { Uso de verbos no } \\
\text { infinitivo }\end{array}$ & $\mathrm{X}$ & $\mathrm{X}$ & $\mathrm{X}$ & $\mathrm{X}$ & $\mathrm{X}$ \\
\hline $\begin{array}{l}\text { Uso do modo } \\
\text { imperativo }\end{array}$ & $\mathrm{X}$ & $\mathrm{X}$ & $\mathrm{X}$ & $X$ & $\mathrm{X}$ \\
\hline $\begin{array}{l}\text { Uso do pronome } \\
\text { "você" }\end{array}$ & $\mathrm{X}$ & $\mathrm{X}$ & $\mathrm{X}$ & $\mathrm{X}$ & $\mathrm{X}$ \\
\hline $\begin{array}{l}\text { Verbos no futuro do } \\
\text { pretérito }\end{array}$ & $\mathrm{X}$ & $\mathrm{X}$ & $\mathrm{X}$ & $\mathrm{X}$ & $\mathrm{X}$ \\
\hline $\begin{array}{l}\text { Conversa com o } \\
\text { leitor }\end{array}$ & $\mathrm{X}$ & & & $\mathrm{X}$ & \\
\hline
\end{tabular}

Fonte: elaborado pelos autores.

Além dos traços estilísticos descritos acima, utilizamos a ferramenta WordCounter $360^{02}$ para analisar e apresentar, de acordo com a nomenclatura utilizada pela própria ferramenta, a quantidade média de frases ${ }^{3}$ e de palavras por frase, do título até o parágrafo final do texto, excluindo o trecho da descrição profissional. Os resultados estão expostos no Quadro 5.

Quadro 5 - Análise da quantidade de frases e palavras por frase

\begin{tabular}{|c|c|c|}
\hline Artigo & Quantidade de frases & Quantidade de palavras por frase \\
\hline A1 & 57 & 19 \\
\hline A2 & 69 & 19 \\
\hline A3 & 119 & 13 \\
\hline A4 & 111 & 15 \\
\hline A5 & 46 & 24 \\
\hline
\end{tabular}

Fonte: elaborado pelos autores.

Identificamos, portanto, algumas diferenças na extensão das frases dos artigos. Enquanto os dois primeiros artigos apresentam a mesma quantidade de palavras por frase, o terceiro apresenta uma menor dimensão. O quarto artigo apresenta uma quantidade de frases menor em relação aos dois primeiros e maior em relação ao terceiro artigo. O quinto artigo possui a menor quantidade de frases e, por outro lado, a maior quantidade de palavras por frase.

\footnotetext{
${ }^{2}$ WORDCOUNTER $360^{\circ}$. [201-]. Contador de palavras e caracteres. Disponível em: <http:// pt.wordcounter360.com/>. Acesso em: 2 dez. 2018.

3 Optamos pela palavra "frase" por ser a nomenclatura apresentada na ferramenta utilizada para a contagem.
} 
Podemos, então, verificar uma certa previsibilidade na quantidade de palavras por frase, entre 13 a 19 palavras. Evidentemente, a quantidade de palavras depende do estilo individual de cada autor, não sendo adequado, dessa maneira, estipular um número a ser seguido.

Após as análises, verificamos que, apesar de os cinco artigos serem de autores diferentes e terem traços particulares, é possível perceber traços de semelhança entre eles. Discutiremos abaixo os três aspectos de semelhança referentes à estrutura composicional, propósito comunicativo e estilo dos artigos. A escolha desses aspectos deve-se ao fato de, na nossa percepção, eles possivelmente representarem as características fundamentais acerca da construção dos artigos publicados no LinkedIn.

Observamos o uso de citações de filmes, livros, músicas e filósofos, perguntas ao longo do texto, agradecimento pela leitura e descrição profissional nas estruturas composicionais dos artigos.

Em relação ao propósito comunicativo, todos os artigos se assemelham quando cada autor escreve para atingir o propósito comunicativo de ajudar os leitores a repensarem suas carreiras. Esse propósito está diretamente relacionado à seleção das palavras e reflexões trazidas no texto.

Sobre o estilo, os traços mais evidentes foram o uso de verbos no infinitivo para ilustrar uma ação, uma atitude, um comportamento geral sem determinação do agente; o uso do imperativo para demonstrar que o autor, de fato, pretende aconselhar o leitor; o uso do pronome "você", bastante visível em todos os artigos, para promover uma proximidade e indicar que o autor está falando diretamente com o leitor; o uso de verbos no futuro no pretérito do indicativo para indicar fatos ocorridos, incerteza, probabilidade em alguns trechos e até mesmo como forma de o autor não se apresentar como uma pessoa impositiva; e o uso de expressões que asseguram um tom conversacional do texto.

Além dessas características textuais, destacamos, também, a forte presença de relatos pessoais nos artigos, tanto com o uso da primeira pessoa do singular quanto do plural. Os autores não escrevem de maneira impessoal, eles se fazem presentes em todo o artigo. Essa característica é importante para a organização do gênero, pois aproxima o autor com seus leitores. Desse modo, o leitor sente uma verdade maior no texto, passando a confiar no autor que relatou suas experiências e suas opiniões.

Identificamos nos artigos um tom de aconselhamento e de orientação. Logo, podemos depreender que os artigos publicados no LinkedIn possuem as funções de esclarecer, de informar e de propor 
v. 9 (3) 277-296 set-dez 2019

reflexões. Por mais que os autores tenham atuações distintas, a linguagem adotada não é direcionada a um público especializado, contudo, não percebemos uma linguagem totalmente direcionada a um público leigo.

Apesar de os autores optarem por um vocabulário simples, os artigos são endereçados a leitores com algum tipo de formação ou, ao menos, com uma vivência profissional mais ampla, declaração que podemos comprovar por meio das seguintes palavras extraídas dos artigos analisados neste estudo: "networking", "hobby", "CLT", "plugin", "feed de notícias", "autopromoção", "planejamento estratégico", "knowhow", "crenças limitantes", "utopia", "histórico de navegação", "conspirar", "clichê", "bradado", "feedbacks", "capitalismo", "cases de sucesso", "millennial", "prodígios do Vale do Silício", "coadjuvante", "freelas", "call", "vangloriar", "\#tbt", "startups", "MBA", "demasia", "canalizar", "responsabilidades laborais" e "autoflagelação".

\section{Considerações finais}

As categorias bakhtinianas de análise dos gêneros do discurso de estrutura composicional, propósito comunicativo e estilo analisadas no corpus deste estudo se assemelham em todos os artigos. Não há uma determinação de como o gênero digital artigo publicado no Linkedin deve ser elaborado, mas podemos perceber, após as análises, que não há tanta diferença quanto à estrutura composicional dos artigos. Verificamos textos constituídos por desenvolvimento numerado, com perguntas, subtítulos, além do uso de citações e relatos pessoais.

Os autores garantem o propósito do artigo por meio de enunciados e palavras. Cada artigo apresenta um estilo próprio, mas não muito destoante dos demais. O uso do pronome "você", de verbos no imperativo e de expressões que dão ao texto um aspecto conversacional realçam as funções de informar, esclarecer, propor reflexões e de aconselhar.

Apesar de o corpus ser reduzido, os dados evidenciaram que o gênero artigo de LinkedIn possui como características a presença de relato pessoal, dos pronomes "eu", "nós" e "você", de verbos no imperativo e de perguntas ao longo do texto. Dessa maneira, as pessoas que publicam artigos no LinkedIn utilizam esses recursos para proporcionar interação com o leitor de maneira facilitada. 
O nosso objetivo foi analisar os artigos para descrever como eles foram construídos e, principalmente, verificar as semelhanças existentes entre eles. Sendo assim, esperamos que estudos futuros sejam realizados acerca do tema para que a nossa compreensão sobre o gênero digital artigo do LinkedIn seja ampliada e, também, para que os utilizadores dessa rede social tenham referências sobre o funcionamento do gênero.

\section{Referências}

ASKEHAVE, Inger; SWALES, John Malcolm. Identificação de gênero e propósito comunicativo: um problema e uma possível solução. In: BEZERRA, Benedito Gomes; BIASI-RODRIGUES, Bernadete; CAVALCANTE, Mônica Magalhães (orgs.). Gêneros e sequências textuais. Recife: Edupe, 2009. p. 221-247.

BAKHTIN, Mikhail. Os gêneros do discurso. Paulo Bezerra (Organização, Tradução, Posfácio e Notas); Notas da edição russa: Seguei Botcharov. São Paulo: Editora 34, 1979/2016.

BARTON, David; LEE, Carmen. Linguagem online: textos e práticas digitais. São Paulo: Parábola Editorial, 2015.

BRANCATELLI, Rodrigo. Entenda o Pulse, siga os Influencers e escreva você também no LinkedIn. Disponível em: <https://www.linkedin.com/pulse/ entenda-o-pulse-siga-os-influencers-brasil-e-escreva-voc\%C3\%AArodrigo/>. Acesso em: 13 nov. 2018.

DEVITT, Amy. Writing Genres. Carbondale IL: SIU Press, 2004.

GIL, Antonio Carlos. Como elaborar projetos de pesquisa. 5. ed. São Paulo: Atlas, 2010.

LIMA, Sandra Mara Moraes. Concepção bakhtiniana de linguagem e de gênero discursivo: uma análise das orientações curriculares de língua portuguesa para o ensino médio. Entretextos (UEL), v. 12, p. 164-177, 2012. Disponível em: <http://www.uel.br/revistas/uel/index.php/entretextos/article/ viewFile/8681/11614>. Acesso em: 30 nov. 2018.

MILLER, Carolyn Rae. Gênero como ação social. In: Ângela Paiva Dionísio, Judith Hoffnagel (Org.). Gênero textual, agência e tecnologia. Tradução de Judith Hoffnagel. São Paulo: Parábola Editorial, 2012. cap. 1, p. 21-41.

MILLER, Carolyn Rae. Comunidade retórica: a base cultural dos gêneros. In: Ângela Paiva Dionísio, Judith Hoffnagel (Org.). Gênero textual, agência e tecnologia. Tradução de Ana Regina Vieira e Judith Hoffnagel. São Paulo: Parábola Editorial, 2012. cap. 2, p. 43-55.

PEDREIRA, Patrick. Os quatro passos para uma carreira de sucesso. Disponível em: <https://www.linkedin.com/pulse/os-4-passos-para-uma-carreira-desucesso-patrick-pedreira/>. Acesso em: 2 out. 2018. 
V. 9 (3)

277-296

set-dez 2019

SOUZA, Matheus de. Vestir a camisa da empresa é legal, mas experimente vestir a sua. Disponível em: <https://www.linkedin.com/pulse/vestir-camisada-empresa-\%C3\%A9-legal-mas-experimente-sua-matheus-de-souza/>. Acesso em: 2 out. 2018.

TARGA, Taís. É possível transformar um hobby em uma profissão? Disponível em: <https://www.linkedin.com/pulse/\%C3\%A9-poss\%C3\%ADvel-transformarum-hobby-em-profiss\%C3\%A30-tais-targa/>. Acesso em: 2 out. 2018.

TERRA, Eberson. Trabalhar para viver ou viver para trabalhar? Disponível em: <https://www.linkedin.com/pulse/trabalhar-para-viver-ou-ebersonterra/>. Acesso em: 2 out. 2018.

VIEIRA, Dimitri. Mudar de carreira: o que fazer quando você não sabe o que fazer? Disponível em: <https://www.linkedin.com/pulse/mudar-de-carreirao-que-fazer-quando-voc\%C $3 \% A A-n \% C 3 \% A 30-$ sabe-dimitri-vieira1f/?originalSubdomain=pt>. Acesso em: 2 out. 2018. 